\title{
PENYELESAIAN PERMASALAHAN KREDIT TANPA AGUNAN (UMKM) DI DENPASAR
}

\author{
Oleh
Ni Made Arini*, Prof. Dr. I Gusti Ngurah Wairocana, SH., MH**, Dr. I Wayan
Wiryawan,SH.,MH** \\ Magister Kenotariatan Universitas Udayana \\ E-mail : madearini2@yahoo.com
}

\author{
ABSTRACT \\ CREDIT PROBLEM SETTLEMENT WITHOUT AGUNAN (UMKM) \\ IN DENPASAR
}

\begin{abstract}
Government of Denpasar city has a collaboration in distributing credit without agunan, namely Memorandum of Understanding (MOU) among Denpasar city government and PT, Bank Pembangunan Daerah Bali and PT. Asuransi Indonesia about micro small development, middle small development and cooperative with credit loan pattern No. Add: 893.3/1919/ORG.0182.107.2006.2, 17/MOU /LPKD/VII/2006 dated $26^{\text {th }}$ of July 2006, government of Denpasar city as a guarantor, however, the existance of Financial Investigation Agency based on governmental regulation of Indonesia Republic Number 54 of 2005, concerning Local Loan Article 4 point 1 that states "Regional Government is prohibited to assigne guarantee for other party loan". Thus, there is a gap about contract agreement with Governmental Regulation of Indonesia Republic Number 54 of 2005 concerning Local Loan.

In relations to this background, so the writer proposes 2 legal problems namely, How is the legal protection toward creditor if it takes place wanprestasi on credit without agunan to UMKM in Denpasar and How is te effort done by bank in case there is a problem with credit without guarantee of UMKM in Denpasar.

This type of study shows that in pursuant to Guarantee Legal Regulation and existing Banking Law, the requirement of guarantee in giving credit by bank is not an absolute prerequisite. If it takes place wanprestasi on credit without agunan UMKM in Denpasar so it will be under responsibility by PT. Askrindo as a guarantee.

The effort done, in case, there is a problem of credit without a guarantee to UMKM in Denpasar, the settlement is done through Non Litigation, namely settlement in rescehduling, prerequsite again and manageable again.
\end{abstract}

Key words: problem of credit settlement, PT. Askrindo, UMKM.

\section{PENDAHULUAN}

\subsection{Latar Belakang Masalah}

Pembangunan ekonomi di Indonesia menempatkan UMKM selalu digambarkan sebagai sektor yang mempunyai peranan yang penting, karena sebagian besar jumlah penduduknya berpendidikan rendah dan hidup dalam kegiatan usaha kecil baik disektor tradisional maupun modern. Namun demikian, usaha pengembangan yang telah dilaksanakan masih belum memuaskan hasilnya, karena pada kenyataannya kemajuan UMKM sangat kecil dibandingkan kemajuan yang dicapai usaha besar.

Pemerintah Kota Denpasar melakukan kerjasama dalam menyalurkan kredit tanpa agunan, yaitu berdasarkan Nota Kesepahaman $(M O U)$ antara Pemerintah Kota Denpasar dan PT. BPD Bali dengan PT. Asuransi Kredit Indonesia tentang Pengembangan Usaha Mikro, Kecil, Menengah dan Koperasi (UMKMK) Dengan Pola Penjaminan Kredit Nomor Add:
893.3/1919/ORG,

0182.107.2006.2, 17/MoU/LPKD/VII/2006 tanggal 26 Juli 2006.

Dengan melihat permasalahan tersebut, maka penulis mencoba untuk melakukan penelitian lebih mendalam untuk mengangkat permasalahan tersebut dengan menuangkan dalam penulisan Tesis yang berjudul PENYELESAIAN PERMASALAHAN KREDIT TANPA AGUNAN.

\subsection{Rumusan Masalah}

Bertitik tolak dari latar belakang permasalahan sebagaimana diuraikan diatas, terdapat berbagai permasalahan yang ingin diberikan penegasan secara lebih mendalam adalah sebagai berikut:

1. Bagaimanakah Perlindungan hukum terhadap kreditur apabila terjadi wanprestasi pada Kredit Tanpa Jaminan pada UMKM di Denpasar?

2. Bagaimana upaya yang dilakukan oleh Bank dalam hal terjadinya 
kemacetan pada kredit tanpa jaminan pada UMKM di Denpasar?

\subsection{Ruang Lingkup Masalah}

Dalam hubungannya dengan permasalahan diatas, akan dibahas mengenai keberadaan kredit tanpa jaminan pada UMKM di kota Denpasar dan perlindungan hukum yang diberikan kepada kreditur dalam menyalurkan Kredit Tanpa Agunan apabila si debitur wanprestasi.

\subsection{Tujuan Penelitian}

Tujuan dari penelitian ini adalah sebagai berikut:

\section{a. Tujuan umum}

1) Memahami secara komprehensif mengenai perkembangan dan pemberdayaan UMKM sebagai salah satu pilar dalam pembangunan ekonomi kerakyatan.

2) Memahami lebih mendalam tentang aspek-aspek hukum perjanjian karedit terutama berkaitan dengan pengembangan dan pemberdayaan UMKM.

\section{b. Tujuan khusus}

1) Untuk mendalami dan menganalisa lebih detai terhadap perlindungan hukum apabila terjadi wanprestasi pada perjanjian kredit tanpa agunan dalam menunjang dan memberdayakan UMKM.

2) Untuk mengalisa dan memahami secara mendalam upaya-upaya yang dapat dilakukan oleh pihak bank apabila terjadi kemacetan dalam pelaksanaan kredit tanpa agunan serta akibat hukum dari perjanjian kredit tersebut.

\subsection{Manfaat Penelitian}

Dari setiap penelitian tentunya terdapat maanfaat yang dapat dipetik dari hal tersebut. Manfaat tersebut yaitu manfaat teoritis dan manfaat praktis.

\subsection{Landasan Teoritis}

Untuk menjawab permasalahan yang ada dalam tesis ini digunakan teori - teori yaitu :

\subsubsection{Teori Perlindungan Hukum}

Teori perlindungan hukum yang dikemukankan oleh Philipus M. Hadjon dikatakan bahwa ada dua macam perlindungan hukum bagi rakyat meliputi : Perlindungan Hukum Preventif dimaksudkan kepada rakyat diberi kesempatan untuk mengajukan keberatan atau pendapatnya sebelum suatu keputusan pemerintah mendapat bentuk yang definitif dan Perlindungan Hukum Represif, dimaksudkan lebih ditujukan dalam penyelesaian sengketa.

\subsubsection{Teori Kepastian Hukum}

Kepastian hukum tidak hanya mensyaratkan keabsahan peraturan hukum yang dibuat melalui kekuasaan, melainkan juga menuntut pada seluruh isinya, dapat diadministrasikan dengan pasti sehingga dapat dilaksanakan.

Asas kepastian hukum adalah asas dalam Negara hukum yang mengutamakan landasan peraturan perundang-undangan, kepastian, dan keadilan dalam setiap kebijakan penyelenggara Negara,termasuk pengelolaan Perusahaan daerah (PD)/ Badan Usaha Milik Daerah (BUMD).

\subsubsection{Teori Tanggung Jawab}

Tanggung jawab tidak lepas dari kewajiban sosial yang mesti dipenuhi oleh perusahaan terhadap masyarakat. Kewajiban yang kemudian ditetapkan undang-undang dilengkapi perkembangan-perkembangan menurut hukum, seperti tanggung jawab perusahaan atau pemilik pabrik terhadap konsumen.

\subsubsection{Teori Perjanjian}

Pasal 1313 KUH Perdata dapat diartikan bahwa suatu perjanjian adalah merupakan suatu perbuatan antara dua orang atau lebih yang melahirkan perikatan dari orang-orang yang berjanji tersebut.

\subsection{Hipotesis}

Adapun hipotesis dari permasalahan tersebut diatas adalah Perlindungan hukum terhadap kreditur (Bank) dalam terjadinya wanprestasi oleh debitur, maka pemerintah daerah selaku penjamin dari debitur (UMKM) harus dapat menyelesaikan persoalan kerugian yang timbul dari perjanjian kredit tersebut.

\subsection{Metode Penelitian \\ 1.8.1. Jenis Penelitan}

Jenis penelitian yang dipergunakan dalam penyusunan tesis ini adalah penelitian hukum empiris yaitu pendekatan permasalahan yang dilihat dari segi aturan-aturan hukum dengan kenyataan-kenyataan yang ada di lapangan, yang kemudian dikaitkan dengan adanya gejala-gejala hukum yang ada didalam kehidupan masyarakat. ${ }^{2}$

\subsubsection{Sifat Penelitian}

Dalam penyusunan tesis ini, dilakukan penelitian yang sifatnya deskriptif. Penelitian deskriptif yaitu penelitian yang berusaha untuk menggambarkan pemecahan masalah yang ada sekarang berdasarkan data-data, sehingga dilakukan kegiatan menyajikan data, menganalisis dan menginterpretasikan. Penelitian deskriptif bertujuan untuk pemecahan masalah secara sistematis dan faktual mengenai fakta-fakta dan sifat-sifat populasi. ${ }^{3}$

${ }^{1 .}$ W. Friedman, 1990, Teori dan Filsafat Hukum, Hukum dan Masalah-Masalah Kontemporer, terjemahan Mohamad Arif. Jakarta, Cetakan I, C.V. Rajawali, hal. 53.

${ }^{2 .}$ Ronny Hanitijo Soemitro, 1983, Metodologi Penelitian Hukum, Cet.I, Ghalia Indonesia, Jakarta, (selanjutnya disingkat Ronny Hanitijo Soemitro I), hal. 45 .

${ }^{3}$ Cholid Narbuko dan Abu Achmadi, 2008, Metodologi Penelitian, Cet.9, Bumi Aksara, Jakarta, hal. 44. 


\subsection{Sumber data}

Sumber data yang dipergunakan adalah sumber data yang berkaitan dengan masalahmasalah khususnya mengenai perlindungan hukum dan upaya penyelesaiannya bila si debitur wanprestasi, adapun sumber data yang dipergunakan berupa:

1) Sumber data primer

Data primer adalah data yang bersumber dari penelitian lapangan yaitu suatu data yang diperoleh langsung dari sumber pertama dilapangan yaitu dari informan.

2) Sumber data sekunder

Data sekunder adalah suatu data yang bersumber dari penelitian kepustakaan, yaitu bersumber dari data-data yang sudah terdokumenkan dalam bentuk bahan-bahan hukum. Baik dalam berupa buku-buku/ literatur, karya tulis, undang-undang, maupun internet yang berkaitan dengan pokok bahasan.

\subsection{Teknik pengumpulan data}

Adapun teknik pengumpulan data yang dipergunakan adalah sebagai berikut :

1) Data primer

Diperoleh dengan melakukan wawancara terhadap pihak-pihak yang terkait. Wawancara disini berarti wawancara secara fisik. ${ }^{4}$ Wawancara dilakukan dengan para informan yang ada kaitannya dengan permasalahan dalam tesis ini, yaitu terhadap BPD Bali dan Dinas Koperasi, Pengusaha Kecil dan Menengah Kota Denpasar.

2) Data sekunder

Dilakukan dengan cara pencatatanpencatatan dari literatur/ buku-buku yang sesuai dengan permasalahan.

\subsubsection{Teknik analisis}

Setelah data-data yang dibutuhkan terkumpul, maka data-data tersebut akan diolah dan dianalisa dengan menggunakan teknik pengolahan data secara kualitatif.

Teknik pengolahan data secara kualitatif dilakukan dengan memilih data dengan kualitasnya untuk dapat menjawab permasalahan yang diajukan. ${ }^{5}$ Selanjutnya untuk penyajiannya dilakukan secara deskriptif analisa yaitu pemaparan secara jelas dan terperinci mengenai penelitian terhadap suatu peristiwa untuk mengetahui keadaan yang sebenarnya.

\section{TINJAUAN UMUM PERJANJIAN KREDIT} BANK

\subsection{Pengertian Perjanjian Kredit dan Dasar Hukumnya}

\subsubsection{Pengertian Perjanjian Kredit}

4. Kartini Kartono, 1983, Pengantar Metode Penelitian Research Sosial, Alumni, Bandung, hal. 171.

${ }^{5 .}$ Ronny Hanitijo Soemitro, 1990, Metodologi Penelitian Hukum dan Jurumetri, Cet.IV, Ghalia Indonesia, Jakarta, selanjutnya disingkat Ronny Hanitijo Soemitro II, hal. 47.
Kredit berasal dari bahasa Romawi credere yang berarti kepercayaan atau credo atau creditum yang berarti saya percaya. Seseorang yang mendapatkan kredit adalah seseorang yang telah mendapatkan kepercayaan dari kreditur. ${ }^{6}$ Unsur - unsur kredit sebagai beikut :

1. Kepercayaan, adalah adanya keyakinan dari pihak bank atas prestasi yang diberikannya kepada debitur yang akan dilunasinya sesuai jangka waktu yang diperjanjikan.

2. Waktu adalah adanya jangka waktu tertentu antara pemberian kredit dan pelunasannya di mana jangka waktu tersebut sebelumnya terlebih dahulu telah disepakati bersama antara pihak bank dengan debitur.

3. Prestasi adalah adanya obyek tertentu berupa prestasi dan kontra prestasi pada saat tercapainya persetujuan atau kesepakatan perjanjian pemberian kredit antara bank dan debitur berupa uang dan bunga.

4. Resiko adalah adanya resiko yang mungkin terjadi selama jangka waktu antara pemberian dan pelunasan kredit tersebut, sehingga untuk mengamankan pemberian kredit dan menutup kemungkinan terjadinya wanprestasi dari debitur diadakan pengikatan jaminan.

Adapun yang menjadi dasar hukum suatu perjanjian kredit adalah :

a. Undang-Undang Nomor 10 Tahun 1998 Tentang Perbankan Lembaran Negara Republik Indonesia Tahun 1998 Nomor 182, Tambahan Lembaran Negara Republik Indonesia Nomor 3790.

b. Undang-Undang Nomor 23 Tahun 1999 Tentang Bank Indonesia Lembaran Negara Republik Indonesia Tahun 1999 Nomor 66.

c. Undang-Undang Nomor 37 Tahun 2004 tetang Kepailitan dan Penundaan Kewajiban Pembayaran Utang Lembaran Negara Republik Indonesia Tahun 2004 Nomor 131, Tambahan Lembaran Negara Republik Indonesia Nomor 4443. KUH Perdata, terdapat dalam buku ke HI Bab I s/d Bab IV yang mengatur tentang perikatan.

\subsubsection{Prinsip-Prinsip Pemberian Kredit}

Adapun prinsip-prinsip yang digunakan untuk melakukan penilaian adalah sebagai berikut: Prinsip 5C yang terdiri atas Character (Watak), Capital (Modal), Capacity (Kemampuan), Condition of Economy (Kondisi Ekonomi), Collateral (Jaminan), Prinsip 4 P, yang terdiri atas Personality, Purpose, Prospect, Payment dan Prinsip 3 R yang terdiri atas Returns atau returning (hasil yang dicapai), Repayment (pembayaran kembali) dan Risk bearing ability (kemampuan untuk menanggung resiko).

Dalam memberikan kredit kepada nasabah, pihak bank berpedoman pada asas-asas dalam perjanjian sebagai berikut, Asas Kebebasan

${ }^{6}$ Mariam Darus Badrulzaman, Aspek hukum perjanjian Kredit bank, Citra Aditya, bandung, hal. 137 
Berkontrak, Asas Konsensualisme, Asas Pacta Sunt Servanda, Asas Itikad Baik (Goede Trouw) dan Asas Kepribadian (Personalitas).

\subsubsection{Jenis - Jenis Perkreditan}

Berdasarkan jenisnya, kredit dapat digolongkan sebagai berikut yaitu kredit menurut sifat penggunaannya yaitu kredit investasi dan kredit modal kerja.

\subsubsection{Prosedur dan Persyaratan Pemberian Kredit oleh Bank}

Untuk memperoleh kredit bank, seorang debitur harus melalui beberapa tahapan yaitu dari tahapan pengajuan aplikasi kredit sampai dengan tahapan penerimaan kredit. Tahapan-tahapan tersebut merupakan suatu proses baku yang berlaku bagi setiap debitur yang membutuhkan kredit bank.

\subsubsection{Hak dan Kewajiban Para Pihak dalam Perjanjian Kredit}

Perjanjian Kredit merupakan suatu hubungan hukum antara para pihak dalam suatu perjanjian, serta merupakan suatu perbuatan hukum yang menimbulkan hak dan kewajiban bagi para pihak dalam suatu perjanjian. Hak dan kewajiban nasabah diwujudkan dalam bentuk prestasi, prestasi yang harus dipenuhi oleh bank dan nasabah adalah prestasi yang telah ditentukan dalam perjanjian antara bank dan nasabah terhadap produk perbankan, semisal tabungan dan deposito.

\section{EKSISTENSI JAMINAN DALAM PEMBERIAN KREDIT OLEH BANK \\ 3.1. Kedudukan Jaminan Dalam Perjanjian Kredit}

\subsubsection{Subyek dan Obyek Jaminan}

Dalam perjanjian jaminan, yang menjadi subyek hukum jaminan adalah pihak debitur (penerima pinjaman / pemberi jaminan) dan pihak kreditur (pemberi kredit / penerima jaminan) sedangkan obyek jaminan adalah jaminan kebendaan dan jaminan perorangan.

\subsubsection{Dasar Hukum Jaminan}

Ketentuan mengenai hukum jaminan di bedakan menjadi 2 (dua), yaitu; ketentuan hukum jaminan yang terdapat dalam KUH Perdata dan KUH Dagang, dan ketentuan hukum jaminan yang terdapat di luar KUH Perdata dan KUH Dagang.

\subsubsection{Jaminan Sebagai Persyaratan Pemberian Kredit}

Agar penerapan jaminan dalam pemberian kredit dapat berjalan dengan baik, maka diperlukan ketentuan-ketentuan hukum mengenai jaminan yang tegas. Dimana ketentuan hukum tersebut dapat memberikan keamanan bagi para pihak yang terlibat dalam perjanjian kredit, khususnya bagi pihak bank selaku kreditur dan nasabah selaku debitur.

\section{PERJANJIAN KREDIT DAN KONSEKUENSI HUKUMNYA}

\subsection{Pemberian Kredit Dengan Jaminan dan Kredit Tanpa Jaminan}

4.1.1. Pemberian Kredit dengan Jaminan

Sebagaimana telah dijelaskan di atas, jika dilihat dari segi jaminannya kredit dapat dibedakan menjadi kredit dengan jaminan dan kredit tanpa jaminan. Seperti yang telah dijelaskan sebelumnya Kredit tanpa jaminan atau Kredit Blanko (unsecured loan) yaitu pemberian kredit tanpa jaminan material (agunan fisik), pemberiannya sangatlah selektif dan ditujukan kepada nasabah besar yang telah teruji bonafiditas, kejujuran dan ketaatannya dalam transaksi perbankan maupun kegiatan usaha yang dijalaninya.

Dalam Peraturan Perundang-Undangan yang berlaku seperti Undang-Undang Nomor 7 Tahun 1992 tentang Perbankan dan Undang-Undang Perubahannya (Undang-Undang Nomor 10 Tahun 1998), pemberian kredit demikian dapat saja direalisasikan, sebab Perundang-Undangan Perbankan yang berlaku sekarang lebih menganut kepada jaminan yang bersifat non fisik, artinya bahwa pemberian kredit dapat dilakukan oleh bank apabila bank mempunyai keyakinan terhadap debitur atas kemampuan, dan kesanggupan debitur untuk melunasi hutangya sesuai dengan yang diperjanjikan.

Kredit tanpa jaminan mengandung lebih besar resiko, sehingga dengan demikian berlaku bahwa semua harta kekayaan debitur baik yang bergerak maupun tidak bergerak yang sudah ada maupun yang akan ada kemudian seluruhnya menjadi jaminan pemenuhan pembayaran hutang.

Bagi dunia Perbankan, Kredit tanpa jaminan merupakan jenis kredit yang mengandung resiko besar, oleh karenanya tidak banyak bank di Indonesia yang mengeluarkan kredit jenis ini. Bank sebagai suatu lembaga penghimpun dana dari dan untuk masyarakat akan menerapkan Prinsip Kehati-hatian Bank dalam setiap pemberian kredit kepada nasabah (debitur). Berlatar-belakang prinsip tersebut banyak Bank mengeluarkan kredit kepada nasabah (debitur) dengan jalan meminta jaminan atau yang dikenal dengan Kredit dengan Jaminan, sebagai salah satu cara meminimalisir resiko kerugian yang akan diderita sebagai akibat nasabah (debitur) tidak dapat melunasi kreditnya sesuai dengan yang telah diperjanjikan.

\subsubsection{Agunan Dan Pengikatannya Sebagai} Perjanjian Tambahan

Bank sebagai suatu lembaga penyalur dana masyarakat, melalui pemberian kredit membutuhkan jaminan sebagai keyakinan bahwa kredit yang diberikan akan kembali sesuai dengan yang diperjanjikan. Jaminan yang dibutuhkan oleh Bank harus memiliki nilai ekonomi sebagai persyaratan.

Agunan merupakan jaminan tambahan yang diperlukan dalam pemberian fasilitas kredit. Hal ini sesuai dengan pengertian agunan yang termuat dalam Pasal 1 angka 23 Undang-Undang Nomor 
10 Tahun 1998 tentang Perubahan Atas UndangUndang Nomor 7 Tahun 1997 Tentang Perbankan, yaitu bahwa agunan adalah jaminan tambahan yang diserahkan nasabah debitur kepada bank dalam rangka pemberian fasilitas kredit atau pembiayaan berdasarkan prinsip syariah. Dengan kedudukannya sebagai jaminan tambahan maka bentuk agunan menurut penjelasan Pasal 8 Undang-Undang Nomor 10 Tahun 1998 tentang Perubahan Atas UndangUndang Nomor 7 Tahun 1992 Tentang Perbankan dapat berupa : “...barang, proyek, atau tagihan yang dibiayai dengan kredit yang bersangkutan.

Melihat kenyataan yang demikian dalam kegiatan perkreditan perbankan, maka agunan memiliki fungsi untuk menjamin pembayaran kredit yang dalam kehidupan dan kegiatan perbankan bertujuan pula untuk mengamankan dana pihak ketiga yang dikelola oleh bank yang bersangkutan, selain itu juga untuk memenuhi ketentuan perkreditan yang dikeluarkan Bank Sentral.

\subsubsection{Akibat Hukum Kredit Yang Diberikan Tanpa Jaminan}

Hak preference yang diterima oleh kreditur (bank) yang memberikan kredit kepada debitur dengan menggunakan prinsip kehati-hatian, menghindarkan bank dari risiko yang akan timbul apabila debitur melakukan wanprestasi.

Sebaliknya dari penjelasan tersebut adalah apabila kreditur (bank) memberikan kredit kepada debitur dengan tidak memperhatikan pentingnya jaminan yang harus diserahkan oleh debitur kepada bank selaku kreditur, maka kreditur dalam hal ini bank akan berada dalam posisi sebagai kreditur konkuren. Sebagai kreditur konkuren, bank memiliki derajat yang sama dengan krediturkreditur lainnya yang berkepentingan dengan jaminan dari debitur sebagai pelunasan hutang. Dalam keadaan yang demikian maka bank harus bersaing dengan kreditur-kreditur lainnya, dimana setelah pelelangan benda jaminan piutang yang menjadi hak bank dari debitur akan dibagi-bagi, sehingga pelunasan hutang debitur kepada kreditur bank mustahil akan terlaksana.

\section{SIMPULAN DAN SARAN}

\subsection{Simpulan}

Berdasarkan uraian dalam bab-bab sebelumnya maka berdasarkan permasalahan yank diajukan dapat ditarik kesimpulan sebagai berikut

1. Berdasarkan ketentuan hukum jaminan dan hukum perbankan yang berlaku, persyaratan jaminan (kebendaan) dalam pemberian kredit oleh bank bukan merupakam syarat mutlak. Dalam setiap pembebanan kredit oleh bank, todak mutlak adanya jaminan kebendaan yang diberikan oleh nasabah (debitur) kepada bank selaku kreditur, selama nasabah (debitur) memenuhi persyaratan kredit yang lain, yang memberikan keyakinan kepada bank bahwa nasabah (debitur) dapat mengembalikan kreditnya tepat pada waktunya.

Apabila terjadi wanprestasi pada kredit tanpa jaminan UMKM di Denpasar maka akan ditanggung oleh PT. Askrindo sebagai penjamin.

2. Upaya hukum yang ditimbulkan apabila kredit diberikan tanpa adanya jaminan dari nasabah (debitur) adalah pihak bank berada dalam posisinya sebagai kreditur konkuren dipersamakan dengan kreditur-kreditur lainnya dalam hal pelunasan hutang kredit, sehingga harus bersaing dengan krediturkreditur lainnya dalam pelunasan hutang kredit. Karena tidak memiliki hak preferensi, maka dapat terjadi hutang kredit. Karena tidak memiliki hak preferensi, maka dapat terjadi hutang kredit tidak dibayarkan secara penuh kepada bank, Karena bank harus berbagi dengan kreditur-kreditur lainya dalam hal pelunasan hutang dari nasabah (debitur).

Upaya yang ditempuh dalam hal terjadinya kemacetan kredit tanpa jaminan pada UMKM di denpasar penyelesaiannya yang dilaksanakan adalan penyelesaian non letigasi yaitu : penyelesaian secara penjadwalan kembali (rescheduling), persyaratan kembali (reconditioning) dan penataan kembali (restructuring).

\subsection{Saran-Saran}

1. Dalam rangka menciptakan kepastian hukum, dan efektifitasnya penegakan hukum dalam bidang hukum Perbankan, maka perlu adanya pengaturan lebih tegas didalam UndangUndang Perbankan, khususnya yang mengatur tentang persyaratan jaminan dalam pemberian kredit oleh bank yang akan memberikan kepastian hukum kepada para pihak yang terkait dengan kredit yang diberikan oleh bank. Bank Indonesia selaku pengawas perbankan nasional, perlu mengeluarkan Surat Edaran Bank Indonesia yang memuat tentang keharusan adanya jaminan dalam setiap pemberian kredit yang dilakukan oleh bank.

2. Dalam rangka pembangunan di bidang ekonomi, sebaiknya setiap kredit yang diberikan oleh bank kepada nasabah 9debitur) selalu disertai dengan adanya jaminan (kebendaan), untuk menghindari bank dari kerugian akibat ketidakmampuan nasabah (debitur) dalam melunasi kreditnya kepada bank sesuai dengan waktu yang telah diperjanjikan. 


\title{
DAFTAR PUSTAKA
}

\section{B UKU}

Achmad Anwari, 1980, Praktik Perbankan di Indonesia (Kredit Investasi), Balai Aksara, Jakarta.

Ahmad Ali, 2006, Menguak Teori Hukum (Legal Theory) dan Teori Peradilan (Judicialprudence), Prenada Media Grup, Jakarta.

Allan Farnsworth and Alfred McCormack, 1982, Contracts, Brown and Compony, Little Boston and Toronto.

Arif Hafis, 1998, Modal Ventura Sebagai Alternatif Pembiayaan, Dalam Majalah Manajemen dan Usahawan Indonesia, Jakarta.

Budiono Kusumohamidjojo, 2001, Panduan untuk Merancang Korarak. Grasindo, Jakarta.

Cholid Narbuko dan Abu Achmadi, 2008, Metodologi Penelitian, Cet.9, Bumi Aksara, Jakarta.

Djuhaendah Hasan, Lembaga Jaminan Kebendaan bagi Tanah dan Benda Lain yang Melekat pada Tanah dalam Konsepsi Penerapan Asas Pemisahan Horizontal. Citra Aditya Bakti, Bandung.

Etty Susilowati, 2007, Kontrak Alih Teknologi pada Industri Manufaktur. Yogyakarta, Genta Press.

Fetter Heffey, 2002, Principles of Contract Law, Thomson Legal and Regulatory Limited, Sidney.

Gustav Radbruch, 1950, Legal Philosophy, Dalam The Legal Philosophies of Lask, diterjemahkan oleh Kurt Wilk, Harvard University Press, Cambridge Massachusetts.

Hans Kelsen, 1995,Teori Hukum Murni Dasar-Dasar Ilmu Hukum Normatif Sebagai Ilmu Hukum Empirik-Deskriptif Alih Bahasa Drs Somardi, Rimdi Press, cetakan I.

Hilaire Mc Coubery \& Nigel D White, 1996, Textbook on Jurisprudence, second edition, Blackstone press Limited Britain,.

H.E. Saefullah, 1998, Beberapa Masalah tentang Tanggung jawab Pengangkutan Udara, Pusat Penerbitan Universitas. LPPM Universitas Islam Bandung, ( UNISBA).

$* * * * *$

Acta Comitas (2017) $1: 127-137$

ISSN : 2502-8960 I e-ISSN : 2502-7573

\section{PEMBERIAN KREDIT BANK DENGAN JAMINAN HAK GUNA BANGUNAN YANG JANGKA WAKTUNYA TELAH BERAKHIR SEDANGKAN PERJANJIAN KREDITNYA BELUM BERAKHIR Oleh :}

\author{
I Gede Etha Prianjaya* \\ NIM 1292461001 \\ Program Magister Kenotariatan Universitas Udayana \\ e-mail : ethaprianjaya@gmail.com \\ Pembimbing I : Prof. Dr. Ibrahim R. SH.,MH.** \\ Pembimbing II : Dr. I Ketut Westra, SH.,M.H.***
}

\begin{abstract}
Bank is a financial institution that has an important role in the economy of a State based on the function of banks as a collector and distributor of public funds, as well as the types of products produced and supplied by the bank have become something significant and convenient enjoyed by people such as the provision of credit. Granting bank credit is stipulated in Law No. 7 of 1992 and its amendment, Law No. 10 of 1998 Article 6 letter b. Loans granted by banks contains a risk, so in practice the bank must pay attention to the principles of what healthy credit is. In order to reduce the risk, collateral for credit is an important factor considered by a bank. Title to a land that can be used as collateral, such as Building Rights stipulated in Article 35 of Law Number 5 of 1960 on Basic Regulation of Agrarian, as one of the land rights by law to have a controlling effect but with time its period must be expired. Expiration of Building Rights being used as a credit security encumbered encumbrance of course would have the legal effect of the existence of security rights itself. Based on that, it will cause problems as follows What is the position of security building rights whose period has ended and the loan is not over and what is the efforts made by the bank to the credit agreement has not ended with the assurance that the right mortgage is over.

This type of research used in this thesis is empirical legal research because there is a gap between the governing rules and the problems that occur in the
\end{abstract}

